\title{
Interleukin 28 Polymorphisms and Hepatocellular Carcinoma Development after Direct Acting Antiviral Therapy for Chronic Hepatitis C
}

\author{
Angelo Simili ${ }^{1,2}$, Giuseppe Mazzella ${ }^{1,2}$, Federico Ravaioli ${ }^{1}$, Davide Festi ${ }^{1}$, Maria Letizia Bacchi-Reggiani ${ }^{3}$, Alberto Porro ${ }^{1}$, \\ Franco Bazzoli ${ }^{1}$, Francesco Azzaroli ${ }^{1,2}$
}

\author{
1) Department of Medical \\ and Surgical Sciences \\ (DIMEC), University of \\ Bologna, Gastroenterology \& \\ Hepatology Unit, S. Orsola- \\ Malpighi University Hospital, \\ Bologna \\ 2) Centre for Applied \\ Biomedical Research (CRBA), \\ University of Bologna, S. \\ Orsola- Malpighi University \\ Hospital, Bologna \\ 3) Department of \\ Experimental, Diagnostic and \\ Specialty Medicine (DIMES), \\ University of Bologna, \\ Italy
}

\author{
Address for correspondence: \\ Federico Ravaioli \\ Department of Medical and \\ Surgical Sciences (DIMEC) \\ University of Bologna \\ Gastroenterology \& \\ Hepatology Unit \\ S. Orsola, Malpighi University \\ Hospital, Bologna, Italy \\ f.ravaioli@unibo.it
}

Received: 04.05.2019

Accepted: 1.08.2019

\section{ABSTRACT}

Background \& Aims: Cirrhotic patients with hepatitis $\mathrm{C}$ virus (HCV) infection remain at risk of developing hepatocellular carcinoma (HCC) even after the sustained virologic response (SVR). We aimed to evaluate whether the IL28 (rs12979860) single nucleotide polymorphism (SNP) may constitute a predisposing genetic factor and to identify the SVR patients at risk of HCC.

Methods: Two hundred patients undergoing DAAs treatment for chronic hepatitis $\mathrm{C}$ with advanced fibrosis (F3F4) were consecutively enrolled. Besides normal routine laboratory testing for HCV, patients' sera were evaluated also for retinol, retinol-binding protein 4 and the following SNPs: PNPLA3 (rs738409), TM6SF2 (rs58542926), MBOAT7 (rs641738), IL28B (rs12979860), TIMP-1 (rs4898), TIMP-2 (rs8179090), NF-kB promoter (rs28362491). Statistical analyses were conducted using Stata/SE 14.2 statistical software (Stata Corp, College Station, TX). Results: Almost all patients (197/200) obtained SVR24. Seventeen patients had a previous history of treated HCC before DAAs. Six patients developed HCC recurrence and five patients developed de novo HCC after a mean period of 18 months since EOT. All these patients had SVR. A significant association between IL28B - TT genotype and HCC development after DAAs therapy was observed (OR 4.728, CI 95\% 1.222 - 18.297, p=0.024). Conclusion: IL28B rs12979860 polymorphism was significantly associated with HCC development after DAAs. Assessment of this SNP may better identify patients at risk of developing HCC after treatment. Further prospective studies are required to confirm these hypotheses.

Key words: IL28 - PNPLA3 - retinol - hepatocellular carcinoma - MBOAT7 - TIMP1 - TIMP2 - viral hepatitis C.

\begin{abstract}
Abbreviations: AFP: $\alpha$-fetoprotein; BMI: body mass index; CEUS: contrast-enhanced ultrasonography; DAA: direct-acting antiviral; ECM: extracellular matrix; EOT: end of treatment; HCC: hepatocellular carcinoma; HCV: Hepatitis C virus; HVPG: hepatic venous pressure gradient; IL28B: interleukin-28B; LSM: liver stiffness measurement; MBOAT7: membrane-bound O-acyltransferase domain-containing protein 7; MELD: model for end-stage liver disease; MMP: matrix metallo-proteinase; NAFLD: non-alcoholic fatty liver disease; NF-kB: nuclear factor kappa-light-chain-enhancer of activated B cells; PNPLA3: patatin-like phospholipase domain containing 3; RBP: retinol binding protein; RBP4: retinol-binding protein 4; SNP: single nucleotide polymorphisms; SVR: sustained virologic response; TIMP-1/2: tissue inhibitor of metalloproteinases 1 and 2; TM6SF2: Transmembrane six superfamily member 2.
\end{abstract}

\section{INTRODUCTION}

Hepatocellular carcinoma (HCC) is one of the leading causes of death worldwide. Despite therapeutic and diagnostic advances, HCC has a poor prognosis. The majority of HCCs develop in the context of chronic hepatitis, particularly in cirrhotic patients, with an annual incidence of $2-8 \%$ [1].
According to the 2017 World Health Organization (WHO) Global Hepatitis Report, around 71 million persons are estimated to be affected by chronic hepatitis $C$ and, in the year 2015, there were more new infections than treatments [2]. Overall, the prevalence of chronic hepatitis $\mathrm{C}$ seems to be decreasing while the liver-related mortality from hepatitis $\mathrm{C}$ virus (HCV) infection is expected to increase [3-5]. HCV eradication, which is deemed feasible in about 15-20 years, is the main road to a global reduction of mortality from $\mathrm{HCV}$ related liver disease and hence from HCC.

However, the elimination of $\mathrm{HCV}$ infection reduces the risk of developing HCC but does not eliminate it. As observed both 
in the interferon and in the direct-acting antiviral (DAA) era, cirrhotic patients remain at risk of developing HCC even after the sustained virologic response (SVR) [6-10].

The identification of HCV patients achieving SVR who remain at risk of developing HCC is now the primary goal, necessary to tailor the follow-up after eradication. Clinical studies have identified several risk factors for HCC development among which male gender, obesity, non-alcoholic fatty liver disease (NAFLD), cirrhosis, alcohol abuse and smoking [1]. More recently, genetic studies have focused on predisposing genetic factors, such as single nucleotide polymorphisms (SNPs), that may impact the pathway to HCC development $[11,12]$

Patatin-like phospholipase domain containing 3 (PNPLA3) is a gene coding for a phospholipase, also known as adiponutrin, involved in the triglyceride and retinol ester metabolism. The rs738409 variant (C>G p.I148M) has been associated with a higher risk of steatosis, cirrhosis and HCC development, independently from other risk factors [13-19]. This variant has been associated with reduced serum levels of retinol and retinol-binding protein 4 (RBP4) [20-24].

Transmembrane 6 superfamily member 2 (TM6SF2) and membrane-bound $\mathrm{O}$-acyltransferase domain-containing protein 7 (MBOAT7) variants, namely genotype rs641738, have been proposed as genetic factors favoring disease progression from steatosis to NASH and cirrhosis in European descent [25].

Interleukin-28B (IL28B) is part of the interferon lambda family, which is essential for the immune response to viruses. In the past, the variant rs12979860 (coding for the T allele) has been associated with an inadequate response to interferon/ ribavirin based therapies while in the DAA era this variant did not seem to impact SVR [26-28]. However, even though with variable results, the IL28B polymorphisms have been associated with different propensities to fibrosis evolution [29]. A recent meta-analysis has suggested that the T-allele of rs12979860 significantly increases the risk of HCC in Caucasians [30].

The Tissue inhibitor of metalloproteinases 1 and 2 (TIMP-1 and TIMP-2) are two genes encoding for matrix metalloproteinase (MMP) inhibitors that are extracellular endopeptidases primarily responsible for the degradation of extracellular matrix (ECM). By regulating the ECM environment, they have a role in fibrosis progression and facilitate tumor cells invasion and migration across the stroma for distant metastasis [31, 32]

Nuclear factor kappa-light-chain-enhancer of activated $B$ cells $(\mathrm{NF}-\mathrm{kB})$ is a transcription factor involved in many processes among which it has a crucial role in the regulation of immune response and inflammation [33]. The SNP rs28362491, a variant in the promoter region, has been associated with progression to cirrhosis and may have a role in HCC development [34].

Based on these premises, we aimed to evaluate whether the SNPs: PNPLA3 (rs738409), TM6SF2 (rs58542926), MBOAT7 (rs641738), IL28B (rs12979860), TIMP-1 (rs4898), TIMP-2 (rs8179090), NF-kB promoter (rs28362491) may represent predisposing factors for HCC development after $\mathrm{HCV}$ eradication with DAAs. Secondarily, we aimed to evaluate whether the PNPLA 3 variant I148M is associated with reduced retinol serum levels, which may constitute a risk factor for tumor development.

\section{METHODS}

\section{Patients}

All patients with chronic hepatitis $\mathrm{C}$ and advanced fibrosis (F3-F4) according to Liver Stiffness Measurement (LSM) >9.5 kilopascals $(\mathrm{kPa})$ [35] who underwent DAAs therapy in our outpatient clinic of an academic hospital were consecutively enrolled starting from 2016. The entire population undergoing DAAs consisted of 344 patients, of whom 200 accepted to enter the study.

SNPs were evaluated in all patients in a single blood draw 24 weeks after the end of treatment (EOT). Besides standard routine laboratory testing for $\mathrm{HCV}$, also serum retinol and retinol-binding protein 4 (RBP4) were evaluated. Patients were advised to avoid any dietary or vitamin supplement containing vitamin A or carotenoids in the three days before the blood draw. Similarly, they were asked to limit meat and egg as well as to avoid interfering food (i.e. tomatoes, carrots, persimmon, eel, liver and offal).

Inclusion criteria for the subsequent statistical analysis were: being treated with DAAs for HCV, older than 18 years and able to understand and sign the informed consent. Exclusion criteria were: unavoidable use of dietary and vitamin supplements, inability to follow the suggested diet in the three days before the blood draw, ethanol abuse, and a diagnosis of rare liver disease, liver transplantation, and bone marrow transplantation. All patients were followed according to the standard of care, and we had no patient lost on follow-up.

\section{Surveillance and HCC assessment}

Before starting antiviral treatment, all patients underwent abdomen ultrasound (US). If a suspicious focal lesion was detected in the liver, the diagnostic workup was completed with contrast-enhanced ultrasonography (CEUS) and subsequent computer tomography (CT) scan or magnetic resonance imaging (MRI) to exclude the presence of HCC. All patients with a history of HCC underwent CT scan or MRI, besides US, to exclude recurrent HCC before starting treatment. In all patients with a history of HCC, the minimum period between the last treatment for HCC and DAAs treatment was at least six months.

All patients were followed up for at least six months after EOT or until HCC development. During the follow-up period, the patients had repeated US evaluation as recommended by the surveillance program guidelines [1]; in case of suspicion of HCC development, CEUS/CT/MRI were carried out to confirm or exclude the presence of HCC.

\section{DNA analysis}

The following SNPs were studied: PNPLA3 (rs738409), TM6SF2 (rs58542926), MBOAT7 (rs641738), IL28B (rs12979860), TIMP-1 (rs4898), TIMP-2 (rs8179090), and NF-kB promoter (rs28362491).

Whole blood was used to extract DNA for SNP evaluation. Samples were frozen to $-20^{\circ} \mathrm{C}$ until use. An aliquot of 400 $\mu \mathrm{L}$ was processed with the semi-automatic instrument 
Maxwell $^{\circledR} 16$ (Promega Corporation, Madison, WI USA), able to purify DNA from 16 samples simultaneously. DNA was purified with a specific kit (Maxwell 16 DNA Purification Kits, Promega Corporation, Madison, WI USA) and then quantified with the spectrophotometer Nanodrop 3.0.0." (Celbio S.P.A, Milano, Italia). SNPs genotyping was performed in a 384 well-plate format on the Sequenom MassARRAY iPLEX platform (Sequenom, San Diego, USA). Primers were designed using the dedicated online software Assay Design v.4.0 (http://www.mysequenom.com, Sequenom Inc., San Diego, CA, USA). After the polymerase chain reaction, analytes were transferred from the plate to the microchip (SpectroCHIP bioarray ${ }^{\circledR}$ ) using the MassARRAY Nanodispenser (Samsung). The loaded microchip was then put into the mass-spectrometer (MALDI-TOF; MatrixAssisted Laser Desorption/Ionisation Time Of Flight; Sequenom Inc., San Diego, CA, USA) for analysis. Data acquisition occurred through dedicated software.

\section{Ethics}

The study was conducted following the Declaration of Helsinki (revision of Edinburgh, 2000) and was approved by our institutional Ethical Committee (approval number 118/2016/U/Tess; amendment EM298/2017/U). All subjects signed written informed consent.

\section{Statistical analysis}

Categorical data were expressed as numbers (percentages) and continuous variables as medians (IQR or range). For group comparison, the Mann-Whitney U test was used for continuous variables and the chi-square test for categorical variables. Spearman rank correlations were calculated to measure and to test the association between SNPs and HCC development. Univariate and multivariate logistic regression analysis was performed to determine predictors of HCC development. Multivariable logistic regression analyses were conducted on variables (sex, ALT, IL28B rs12979860, Retinol, RBP) that reached $\mathrm{p}<0.2$ at univariate analysis. Model discrimination was assessed calculating the Area under the Receiver Operator Characteristic (ROC) curve, whereas model calibration has been determined by the Hosmer-Lemeshow (H-L) chi-square test. P-values less than 0.05 were considered statistically significant. The statistical analysis was conducted using Stata/ SE (Version 14.2; Stata Corp, Texas, U.S.A.).

\section{RESULTS}

The demographic and clinical characteristics of the population under study are reported in Table I.

Almost all patients (197/200) obtained SVR at 24 months. Seventeen patients $(8.8 \%)$ were treated for HCC before DAAs treatment (10 surgery, 9 TACE/PEI, 4 RFA) and 6 of them (3\% overall; $35.29 \%$ of previously treated HCC) developed a recurrence (previous treatment: 4 surgery, 1 PEI, 1 RFA) after a mean period of 18 months from EOT. Five (2.5\%) patients without a history of liver malignancy developed HCC after DAAs therapy after a mean period of 18 months after EOT. All patients who developed HCC had obtained SVR24 and none of these showed HCV re-infection.
Analyzing distribution of the genetic risk factors under study, a significant difference was found for IL28 between patients without HCC and those with recurrence or de novo HCC after DAAs; MBOAT7 resulted significant only in the subgroup of patients with HCC recurrence and without history of HCC while TIMP1 was significant only in patients with HCC recurrence (Table II). However, when we analyzed the correlation between the studied SNPs and HCC we found no significant association (Table III).

Finally, in multivariable logistic regression analysis (Area under ROC curve $=0.7182$; $\mathrm{H}$-L test $\mathrm{p}=0.7828$ ) the only variables significantly associated with HCC development in 11 patients after DAAs were IL28B - TT genotype (OR 4.728; CI 95\% 1.222 - 18.297; $\mathrm{p}=0.024$ ) and retinol (OR: 0.357; CI 95\% $=0.141-0.905 ; \mathrm{p}=0.030)$. Concerning retinol, each increment of $1 \mu \mathrm{mol} / \mathrm{L}$ resulted in a decreased risk of HCC development. In fact, patients developing HCC had significantly lower levels of serum retinol compared to those who did not develop it [0.90 (0.6-1.35) vs $1.2(0.9-1.5) ; \mathrm{p}=0.046]$. In our population, we found no association between PNPLA 3 variant I148M and reduced retinol serum levels.

\section{DISCUSSION}

Recent literature data debate the initial reports of increased frequency of de novo HCC development following antiviral treatment with DAAs for HCV infection $[9,36]$. New studies reported no significant increase in recurrence and a decreased incidence of de novo HCC development after SVR in cirrhotic patients treated with DAA [7,37-39]. Recently, a comprehensive cohort study found an incidence of HCC following DAAs treatment for $\mathrm{HCV}$ of $1.82 \%$ with a $76 \%$ reduction in the risk of tumor development in patients with SVR [7]. Furthermore, the authors found no significant difference in tumor biology between early and delayed HCC nor any significant factor differentiating patients who developed the tumor during treatment or later during follow-up [7]. This study suggested that SVR reduced the risk of HCC development, but that the risk is not zero. Similar results have also been published in two extensive cohort studies [40,41].

These findings are in line with the data obtained with the interferon/peg interferon-based treatments, when SVR was associated with a significant reduction in the risk of HCC development, but the risk was not eliminated [42-44]. Nowadays we are treating with DAAs more severe patients compared to those treated with interferon/peginterferon. Therefore, given the fact that a small subset of cirrhotic patients achieving SVR will still develop HCC, it is essential to identify the patients at risk that may benefit from a closer follow-up. On the other hand, identifying patients at low or no risk may save financial resources by tailoring monitoring and follow-up.

In the present study, we aimed to identify SNPs that may constitute a risk factor for HCC development after DAAs treatment. We selected 7 SNPs dealing with immune response, metabolic factors, extracellular matrix and inflammatory pathways that have been suggested to be related to tumor development. Secondarily, we evaluated serum retinol levels that have been related to tumor development of different kinds $[22,23,45-47]$ and with the PNPLA3 variant I148M [21, 24]. 
Table I. Characteristics of the studied population.

\begin{tabular}{|c|c|c|c|c|c|c|}
\hline & $\begin{array}{l}\text { Whole population } \\
\qquad(\mathrm{n}=200)\end{array}$ & $\begin{array}{l}\text { Patients without HCC } \\
\qquad(\mathrm{n}=178)\end{array}$ & $\begin{array}{l}\text { Patients with HCC } \\
\qquad(\mathrm{n}=22)\end{array}$ & $\begin{array}{l}\text { HCC after DAAs } \\
\text { treatment }(n=11)\end{array}$ & $\begin{array}{c}\text { p-value } \\
\text { (HCC vs } \\
\text { Non-HCC) }\end{array}$ & $\begin{array}{c}\text { p-value (HCC } \\
\text { after DAAs } \\
\text { treatment vs } \\
\text { Non-HCC) }\end{array}$ \\
\hline Gender (M/F) & $104 / 96$ & $87 / 91$ & $17 / 5$ & $9 / 2$ & 0.019 & 0.045 \\
\hline Age & $65.0(55.0-77.0)$ & $66.0(55.0-77.0)$ & $65.0(54.75-77.25)$ & $59(55-68)$ & 0.6716 & 0.3799 \\
\hline BMI & $24.5(23.0-26.5)$ & $24,5(22.92-26.35)$ & $24.8(23.25-27.57)$ & $25.9(23.4-27.8)$ & 0.269 & 0.3065 \\
\hline Diabetes type II & $64(32 \%)$ & $53(29 \%)$ & $11(44 \%)$ & $5(55.6 \%)$ & 0.4029 & 0.111 \\
\hline $\begin{array}{l}\text { Arterial } \\
\text { hypertension }\end{array}$ & $56(28 \%)$ & $48(27 \%)$ & $8(33 \%)$ & $4(44.4 \%)$ & 0.6162 & 0.228 \\
\hline Steatosis by US & $90(45 \%)$ & $82(46 \%)$ & $8(36 \%)$ & $4(36.4 \%)$ & 0.3881 & 0.1584 \\
\hline ALT & $63.5(37.0-93.0)$ & $56.0(34.5-82.0)$ & $69.0(56.5-128.5)$ & $69(62-115)$ & 0.034 & 0.1557 \\
\hline AST & $55.5(36.5-84.0)$ & $55.0(36.0-82.0)$ & $97.0(41.0-136.0)$ & $54(41-124)$ & 0.1096 & 0.6798 \\
\hline$\gamma$-GT & $26.0(20.0-44.0)$ & $26.0(20.0-42.0)$ & $31.0(21.0-68.0)$ & $31(22-69)$ & 0.2446 & 0.4105 \\
\hline HCV-RNA & $\begin{array}{c}1408155.5 \\
(460160.0-2640713.0)\end{array}$ & $\begin{array}{c}1610680.0 \\
(540090.0-2679477.25)\end{array}$ & $\begin{array}{c}958798.0 \\
(298797.0-2141599.25)\end{array}$ & $\begin{array}{c}5391606 \\
(123501-5727025)\end{array}$ & 0.3505 & 0.3160 \\
\hline Creatinine & $0.78(0.69-0.89)$ & $0.78(0.7-0.88)$ & $0.75(0.67-0.93)$ & $0.72(0.58-0.75)$ & 0.5325 & 0.1286 \\
\hline AFP & $4.35(2.75-6.9)$ & $4.4(2.67-6.55)$ & $4.25(3.3-7.1)$ & $3.95(3.1-6.3)$ & 0.3509 & 0.8474 \\
\hline Platelets & $\begin{array}{c}135.0 \\
(98.75-180.25)\end{array}$ & $\begin{array}{c}139.0 \\
(101.0-188.0)\end{array}$ & $\begin{array}{c}118.5 \\
(90.0-155.0)\end{array}$ & $155(119-186)$ & 0.3485 & 0.6660 \\
\hline Albumin & $3.89(3.5-4.1)$ & $3.9(3.57-4.13)$ & $3.6(3.48-3.82)$ & $3.77(3.49-4)$ & 0.4126 & 0.5521 \\
\hline Bilirubin & $0.8(0.6-1.23)$ & $0.8(0.62-1.12)$ & $0.99(0.53-1.55)$ & $0.58(0.46-1.03)$ & 0.9718 & 0.1638 \\
\hline MELD & $8.0(7.0-10.0)$ & $8.0(7.0-10.0)$ & $9.0(7.0-9.43)$ & $7(7-9)$ & 0.5186 & 0.3962 \\
\hline Liver stiffness $(\mathrm{kPa})$ & $14.0(10.5-20.75)$ & $13.45(10.4-20.15)$ & $22.6(16.9-27.07)$ & $22.6(18.2-25.4)$ & 0.0027 & 0.0167 \\
\hline Fib4 & $4.26(2.45-7.26)$ & $4.2(2.4-7.0)$ & $6.43(4.16-8.8)$ & $5.58(4.42-6.76)$ & 0.0300 & 0.0467 \\
\hline HVPG & $12.0(7.0-14.25)$ & $12.0(7.75-14.25)$ & $12.0(8.25-21.0)$ & $7(7-12)$ & 0.6667 & 0.3121 \\
\hline Indocyanine green & 16.75 (11.6-29.9) & $16.35(11.45-30.25)$ & $17.45(11.8-29.9)$ & $14.2(8.9-64.4)$ & 0.6510 & 0.9056 \\
\hline Retinol & $1.2(0.8-1.5)$ & $1.2(0.9-1.5)$ & $0.9(0.6-1.35)$ & $0.8(0.5-1.1)$ & 0.046 & 0.0208 \\
\hline $\begin{array}{l}\text { Retinol-binding } \\
\text { protein } 4\end{array}$ & $3.5(2.7-4.2)$ & $3.5(2.8-4.2)$ & $2.9(2.27-3.9)$ & $2.5(1.9-3.9)$ & 0.043 & 0.0424 \\
\hline
\end{tabular}

Results are expressed as Median and IQR. AFP: alpha-fetoprotein; ALT: alanine aminotransferase; AST: aspartate aminotransferase; BMI: body mass index; DAAs: direct antiviral agents: Fib4: fibrosis 4 index; $\gamma$-GT: gamma glutamyltransferase; HCC: hepatocellular carcinoma; HVPG: hepatic venous pressure gradient; MELD: model for end-stage liver disease

Surprisingly, we did not find any significant association between the majority of the selected SNPs and HCC development, nor between serum retinol levels and PNPLA3 variant I148M. However, this latter result may have been biased by the fact that the majority of patients had advanced fibrosis, and in this case, serum retinol may not reflect liver storage [48].

Only IL28B TT was significantly associated with HCC development after DAAs treatment. IL28B genotype has long been evaluated as a factor conditioning response to interferonbased treatments, with genotype CC associated with more favorable results in terms of SVR $[28,49,50]$. When DAAs became available, this genotype was no longer a limiting factor since the potency of the new drugs overcame this factor of non-response [51]. IL-28 or interferon lambda is a type III interferon, an essential immune mediator that has been shown to have both antiviral as well as anti-tumor activity [52-54]. The precise mechanisms underlying these properties are still not completely unraveled. Concerning $\mathrm{HCV}$, it has been demonstrated that IL28 interferes with both entry [55] and replication [56-57] of the virus into the cell supporting its impact in $\mathrm{HCV}$ clearance, mainly in genotype 1, in the era of PEGylated interferons [49]. The high potency of DAAs with
SVRs above $90 \%$ suggested that even not optimal individual immune responses can be overcome by these drugs, making IL28B genotyping not necessary. The antitumor activity is thought to imply the same mechanisms elucidated for type I interferons, inducing cell apoptosis and cell cycle arrest [52]. It has been previously shown that the IL28B CT/TT polymorphisms were associated with progression to cirrhosis and HCC in viral hepatitis $\mathrm{C}$ suggesting that the presence of these alleles represent a risk factor for HCC development coupled to cirrhosis per se [58]. It is therefore tempting to speculate that in cirrhotic individuals carrying the unfavorable IL28 genotypes this higher susceptibility to tumor development might be maintained after viral eradication because of a less effective immune response.

IL28B codes for a member of the interferon lambda family, these molecules have essential functions in several biological events. They degrade viral genetic material and block viral replication showing antiviral effects $[59,60]$. Beside the antiviral properties, interferon lambda shows other antitumor activities such as cell cycle arrest, apoptosis induction, enhancement of Natural Killer activity and up-regulation of major histocompatibility complex, class I (MHC-I) $[59,60]$. 
Table II. Correlation beween HCC post daa and SNPS

\begin{tabular}{|c|c|c|c|c|c|c|c|c|}
\hline $\begin{array}{l}\text { Spearman's } \\
\text { rho } \\
\text { p-value }\end{array}$ & $\begin{array}{c}\text { HCC post } \\
\text { DAA }\end{array}$ & $\begin{array}{l}\text { PNPLA3 } \\
\text { (rs738409) }\end{array}$ & $\begin{array}{c}\text { TM6SF2 } \\
\text { (rs58542926) }\end{array}$ & $\begin{array}{l}\text { MBOAT7 } \\
\text { (rs641738) }\end{array}$ & $\begin{array}{c}\text { IL28B } \\
\text { (rs12979860) }\end{array}$ & $\begin{array}{l}\text { TIMP-1 } \\
\text { (rs4898) }\end{array}$ & $\begin{array}{c}\text { TIMP-2 } \\
\text { (rs8179090) }\end{array}$ & $\begin{array}{c}\text { NF-kB } \\
\text { promoter } \\
\text { (rs28362491) }\end{array}$ \\
\hline $\begin{array}{l}\text { HCC post } \\
\text { DAA }\end{array}$ & 1 & & & & & & & \\
\hline $\begin{array}{l}\text { PNPLA3 } \\
\text { (rs738409) }\end{array}$ & $\begin{array}{l}0.0674 \\
0.3427\end{array}$ & 1 & & & & & & \\
\hline $\begin{array}{l}\text { TM6SF2 } \\
\text { (rs58542926) }\end{array}$ & $\begin{array}{l}-0.0360 \\
0.6131\end{array}$ & $\begin{array}{l}0.1434 \\
0.0428\end{array}$ & 1 & & & & & \\
\hline $\begin{array}{l}\text { MBOAT7 } \\
\text { (rs641738) }\end{array}$ & $\begin{array}{l}-0.0134 \\
0.8508\end{array}$ & 0.8259 & $\begin{array}{l}0.0032 \\
0.9637\end{array}$ & 1 & & & & \\
\hline $\begin{array}{l}\text { IL28B } \\
\text { (rs12979860) }\end{array}$ & 0.2709 & 0.1567 & 0.0359 & $\begin{array}{l}0.0696 \\
0.3271\end{array}$ & 1 & & & \\
\hline $\begin{array}{l}\text { TIMP-1 } \\
\text { (rs4898) }\end{array}$ & $\begin{array}{l}0.0731 \\
0.3034\end{array}$ & $\begin{array}{l}0.0597 \\
0.4013\end{array}$ & $\begin{array}{l}0.0155 \\
0.8275\end{array}$ & $\begin{array}{l}0.0785 \\
0.2691\end{array}$ & $\begin{array}{l}0.1656 \\
0.0191\end{array}$ & 1 & & \\
\hline $\begin{array}{l}\text { TIMP-2 } \\
\text { (rs8179090) }\end{array}$ & $\begin{array}{l}0.0563 \\
0.4285\end{array}$ & $\begin{array}{l}0.0945 \\
0.1833\end{array}$ & $\begin{array}{l}0.2586 \\
0.0002\end{array}$ & $\begin{array}{l}0.1023 \\
0.1493\end{array}$ & $\begin{array}{l}0.0114 \\
0.8725\end{array}$ & $\begin{array}{l}0.0519 \\
0.4657\end{array}$ & 1 & \\
\hline $\begin{array}{l}\text { NF-kB } \\
\text { promoter } \\
\text { (rs28362491) }\end{array}$ & 0.3173 & 0.2507 & 0.8736 & 0.3808 & 0.6071 & 0.6373 & 0.2665 & 1 \\
\hline
\end{tabular}

DAAs: direct antivirals agents; HCC: hepatocellular carcinoma; IL28B: interleukin-28B; MBOAT7: membrane-bound O-acyltransferase domaincontaining protein 7; NF-kB: nuclear factor kappa-light-chain-enhancer of activated B cells; PNPLA3: patatin-like phospholipase domain containing 3; TIMP-1/2: tissue inhibitor of metalloproteinases 1 and 2; TM6SF2: transmembrane six superfamily member 2.

It seems logical that a less active TT genotype determining a less effective innate antiviral response as well as a defective anti-tumor activity may constitute a significant risk factor for HCC development in cirrhotic patients despite achieving SVR.

An Italian study evaluated the association between the rs12979860 IL28B polymorphism and HCC development in chronic hepatitis C patients enrolled in the years 1989 - 1992 and followed up for a mean of 14.8 years [61]. The authors did not find any association; however, of the originally enrolled patients (465), only 264 accounted for the final results undermining the reliability of the results. Furthermore, patients were enrolled and treated in the pre-DAAs era [61].

A previous Asian study evaluating the IL28B rs12979860 polymorphism in a vast population with $\mathrm{HCV}$ treated with PEGylated interferon plus ribavirin reported an association with HCC development in patients without SVR [62]. However, response rates with PEGylated interferon plus ribavirin are slightly different from those obtained with DAAs and a significant proportion of patients (the more severe) who would now obtain an SVR are left out. Looking at the whole population, the hazard ratio of 1.59 (95\%CI 1.01-2.51, $\mathrm{p}=0.046$ ) at multivariate analysis is reported for the association with HCC development after treatment [63]. A recent metaanalysis evaluating the association of the IL28B rs12979860 polymorphism with HCC independently from treatment or etiology found that this association is stronger in Caucasians than in Asians [30]. Therefore, we think that the results of the study conducted by Chang et al. [30] are comparable to ours.

Obviously, HCC development is a biological process that encompasses several different settings, and other SNPs are expected to associate with tumor development after SVR with DAAs. To our knowledge, at least other two SNPs, TLL1 and MICA, have been reported to be associated with HCC after SVR $[64,65]$. Therefore, the combined evaluation of different SNPs may further enhance our capability of identifying patients at risk of developing HCC despite SVR.

We should also not forget the other known risk factors predicting an increased probability of HCC development, such as older age, lower platelet count, high a-fetoprotein (AFP) levels, non-improvement of liver fibrosis/liver stiffness, HBV, smoking, and coexistence of nonalcoholic steatohepatitis [66-67].

The present study suffers because of a relatively low number of patients with HCC post DAA treatment and a mean followup period below two years that may have limited the number of cases and subgroup analyses. However, the population was well studied and characterized and an increase in the number of cases is unlikely to change the obtained results.

\section{CONCLUSION}

We found a significant association of the IL28B rs12979860 polymorphism with HCC development after SVR obtained 
Table III. Genetic risk factors after DAAS therapy

\begin{tabular}{|c|c|c|c|c|c|c|c|c|c|c|c|}
\hline & $\begin{array}{l}\text { Patients } \\
\text { without } \\
\mathrm{HCC} \\
\mathrm{N}=178\end{array}$ & $\begin{array}{l}\text { Patients } \\
\text { with } \\
\text { HCC } \\
\mathrm{N}=22\end{array}$ & $\begin{array}{l}\text { HCC patients } \\
\text { treated with } \\
\text { DAA without } \\
\text { recurrence } \\
\mathrm{N}=11\end{array}$ & $\begin{array}{l}\text { HCC patients } \\
\text { treated with } \\
\text { DAA with } \\
\text { recurrence } \\
\mathrm{N}=6\end{array}$ & $\begin{array}{l}\text { HCC patients } \\
\text { treated with } \\
\text { DAA without } \\
\text { history of HCC } \\
\mathrm{N}=5\end{array}$ & $\begin{array}{l}\text { HCC after } \\
\text { DAAs } \\
\text { treatment } \\
\mathrm{N}=11\end{array}$ & $\begin{array}{l}\text { p- } \\
\text { value }^{\S}\end{array}$ & $\begin{array}{l}\text { p- } \\
\text { value }^{*}\end{array}$ & $\begin{array}{l}\mathrm{p}- \\
\text { value }^{\mathrm{E}}\end{array}$ & $\begin{array}{l}\text { p- } \\
\text { value }^{\circ}\end{array}$ & $\begin{array}{l}\text { p- } \\
\text { value }^{\#}\end{array}$ \\
\hline $\begin{array}{l}\text { PNPLA3 } \\
\text { (rs738409) } \\
(\mathrm{n}, \%)\end{array}$ & $89(50)$ & $13(59)$ & $7(64)$ & $4(67)$ & $2(40)$ & $7(64)$ & 0.501 & 0.537 & 0.682 & 0.505 & 0.537 \\
\hline $\begin{array}{l}\text { TM6SF2 } \\
\text { (rs58542926) } \\
(n, \%)\end{array}$ & 158 (89) & $19(86)$ & $9(81.8)$ & $6(100)$ & $4(80)$ & $10(91)$ & 0.724 & 0.164 & 0.496 & 0.460 & 0.649 \\
\hline $\begin{array}{l}\text { MBOAT7 } \\
\text { (rs641738) } \\
(\mathrm{n}, \%)\end{array}$ & $45(25)$ & $3(14)$ & $2(18)$ & $1(17)$ & $0(0)$ & $2(18)$ & 0.296 & 0.455 & 0.0001 & 0.0001 & 0.455 \\
\hline $\begin{array}{l}\text { IL28B } \\
(\text { rs12979860) } \\
(n, \%)\end{array}$ & $53(30)$ & $6(27)$ & $3(27)$ & $2(33)$ & $1(20)$ & $2(18)$ & 0.513 & 0.581 & 0.003 & 0.001 & 0.0001 \\
\hline $\begin{array}{l}\text { TIMP-1 } \\
(\mathrm{rs} 4898)(\mathrm{n}, \\
\%)\end{array}$ & $62(35)$ & $10(46)$ & $3(27)$ & $5(83)$ & $2(40)$ & $7(64)$ & 0.352 & 0.751 & 0.025 & 0.573 & 0.102 \\
\hline $\begin{array}{l}\text { TIMP-2 } \\
\text { (rs8179090) } \\
(n, \%)\end{array}$ & $157(88)$ & $22(100)$ & $11(100)$ & $6(100)$ & $5(100)$ & $11(100)$ & 0.137 & 0.615 & 0.478 & 0.540 & 0.615 \\
\hline $\begin{array}{l}\text { NF-kB } \\
\text { promoter } \\
\text { (rs28362491) } \\
(n, \%)\end{array}$ & $78(44)$ & $12(55)$ & $7(64)$ & $4(67)$ & $1(20)$ & $5(46)$ & 0.371 & 0.226 & 0.409 & 0.392 & 0.577 \\
\hline
\end{tabular}

with DAAs, suggesting that assessment of this SNP is advisable to identify patients at risk of tumor development after treatment. An algorithm, including genetic background and the other variables associated with HCC development, may help the clinician to tailor a more stringent follow-up of patients at higher risk. Further prospective studies are required to confirm these hypotheses.

Conflicts of interests: None to declare.

Authors' contributions: G.M, F.D., F.B.,F.A. concept and design of the study; A.S, F.R., A.P., F.A. data acquisition; A.S., F.R., M.L.B.R. statistical analysis; A.S., F.A. DNA analyses and genotyping in the laboratory; A.S., F.R., F.A. data analysis and drafting the manuscript. F.R. is the guarantor of the article. All authors critically revised the manuscript, approved the final version to be published, and agree to be accountable for all aspects of the work, including the authorship list.

Acknowledgments: This study received partial financial support from the University of Bologna (RFO).

\section{REFERENCES}

1. Tang A, Hallouch O, Chernyak V, Kamaya A, Sirlin CB. Epidemiology of hepatocellular carcinoma: target population for surveillance and diagnosis. Abdom Radiol (NY) 2018;43:13-25. doi:10.1007/s00261017-1209-1

2. World Health Organization (WHO). Global Hepatitis Report 2017. 2017. Available at: https://apps.who.int/iris/handle/10665/255016
3. Petruzziello A, Marigliano S, Loquercio G, Cacciapuoti C. Hepatitis $\mathrm{C}$ virus (HCV) genotypes distribution: an epidemiological up-date in Europe. Infect Agent Cancer 2016;11:53. doi:10.1186/s13027-016-0099-0

4. Petruzziello A, Marigliano S, Loquercio G, Cozzolino A, Cacciapuoti C. Global epidemiology of hepatitis $\mathrm{C}$ virus infection: An up-date of the distribution and circulation of hepatitis $\mathrm{C}$ virus genotypes. World J Gastroenterol 2016;22:7824-7840. doi:10.3748/wjg.v22.i34.7824

5. Gower E, Estes C, Blach S, Razavi-Shearer K, Razavi H. Global epidemiology and genotype distribution of the hepatitis $\mathrm{C}$ virus infection. J Hepatol 2014;61(1 Suppl):S45-S57. doi:10.1016/j. jhep.2014.07.027

6. Maan R, Feld JJ. Risk for Hepatocellular Carcinoma After Hepatitis C Virus Antiviral Therapy With Direct-acting Antivirals: Case Closed? Gastroenterology 2017;153:890-892. doi:10.1053/j. gastro.2017.08.052

7. Kanwal F, Kramer J, Asch SM, Chayanupatkul M, Cao Y, El-Serag HB. Risk of Hepatocellular Cancer in HCV Patients Treated With Direct-Acting Antiviral Agents. Gastroenterology 2017;153:996-1005. doi:10.1053/j.gastro.2017.06.012

8. Cabibbo G, Petta S, Calvaruso V, et al. Is early recurrence of hepatocellular carcinoma in HCV cirrhotic patients affected by treatment with direct-acting antivirals? A prospective multicentre study. Aliment Pharmacol Ther 2017;46:688-695. doi:10.1111/apt.14256

9. Conti F, Buonfiglioli F, Scuteri A, et al. Early occurrence and recurrence of hepatocellular carcinoma in HCV-related cirrhosis treated with direct-acting antivirals. J Hepatol 2016;65:727-733. doi:10.1016/j. jhep.2016.06.015

10. Azzaroli F, Accogli E, Nigro G, et al. Interferon plus ribavirin and interferon alone in preventing hepatocellular carcinoma: a prospective 
study on patients with HCV related cirrhosis. World J Gastroenterol 2004;10:3099-3102. doi:10.3748/wjg.v10.i21.3099

11. Howell J, Thompson AJ. Hepatocellular Carcinoma After Sustained Virologic Response: Leave No One Behind. Gastroenterology 2017;152:1282-1284. doi:10.1053/j.gastro.2017.03.025

12. Nahon P, Zucman-Rossi J. Single nucleotide polymorphisms and risk of hepatocellular carcinoma in cirrhosis. J Hepatol 2012;57:663-674 doi:10.1016/j.jhep.2012.02.035

13. Ghalamkari S, Sharafi H, Alavian SM. Association of PNPLA3 rs738409 polymorphism with Liver Steatosis but not with Cirrhosis in Patients with HBV Infection: Systematic Review with Meta-analysis. J Gene Med 2018;20(1). doi:10.1002/jgm.3001

14. Ali M, Yopp A, Gopal P, et al. A Variant in PNPLA3 Associated With Fibrosis Progression but not Hepatocellular Carcinoma in Patients With Hepatitis C Virus Infection. Clin Gastroenterol Hepatol 2016;14:295300. doi:10.1016/j.cgh.2015.08.018

15. Balasus D, Way M, Fusilli C, et al. The association of variants in PNPLA3 and GRP78 and the risk of developing hepatocellular carcinoma in an Italian population. Oncotarget 2016;7:86791-86802. doi:10.18632/ oncotarget. 13558

16. Zhang $\mathrm{S}, \mathrm{Wu} \mathrm{H}, \mathrm{Wu} \mathrm{X}$, et al. Association between PNPLA3 rs738409 polymorphisms and risk of hepatocellular carcinoma and its development in patients with cirrhosis: a meta-analysis. Int J Clin Exp Med 2015;8:6638-6649.

17. Singal AG, Manjunath H, Yopp AC, et al. The effect of PNPLA3 on fibrosis progression and development of hepatocellular carcinoma: a metaanalysis. Am J Gastroenterol 2014;109:325-334. doi:10.1038/ajg.2013.476

18. Xu R, Tao A, Zhang S, Deng Y, Chen G. Association between patatin-like phospholipase domain containing 3 gene (PNPLA3) polymorphisms and nonalcoholic fatty liver disease: a HuGE review and meta-analysis. Sci Rep 2015;5:9284. doi:10.1038/srep09284

19. Fan JH, Xiang MQ, Li QL, Shi HT, Guo JJ. PNPLA3 rs738409 Polymorphism Associated with Hepatic Steatosis and Advanced Fibrosis in Patients with Chronic Hepatitis C Virus: A Meta-Analysis. Gut Liver 2016;10:456-463. doi:10.5009/gnl15261

20. Mateos-Munoz B, Garcia-Martin E, Torrejon MJ, et al. GC Gene Polymorphism and Unbound Serum Retinol-Binding Protein 4 Are Related to the Risk of Insulin Resistance in Patients With Chronic Hepatitis C: A Prospective Cross-Sectional Study. Medicine (Baltimore) 2016;95:e3019. doi:10.1097/MD.0000000000003019

21. Mondul A, Mancina RM, Merlo A, et al. PNPLA3 I148M Variant Influences Circulating Retinol in Adults with Nonalcoholic Fatty Liver Disease or Obesity. J Nutr 2015;145:1687-1691. doi:10.3945/ jn.115.210633

22. Clemente C, Elba S, Buongiorno G, Berloco P, Guerra V, Di Leo A. Serum retinol and risk of hepatocellular carcinoma in patients with child-Pugh class A cirrhosis. Cancer Lett 2002;178:123-129. doi:10.1016/s0304-3835(01)00843-6

23. Newsome PN, Beldon I, Moussa Y, et al. Low serum retinol levels are associated with hepatocellular carcinoma in patients with chronic liver disease. Aliment Pharmacol Ther 2000;14:1295-1301. doi:10.1046/ j.1365-2036.2000.00849.x

24. Pirazzi C, Valenti L, Motta BM, et al. PNPLA3 has retinyl-palmitate lipase activity in human hepatic stellate cells. Hum Mol Genet 2014;23:4077-4085. doi:10.1093/hmg/ddu121

25. Mancina RM, Dongiovanni P, Petta S, et al. The MBOAT7-TMC4 Variant rs641738 Increases Risk of Nonalcoholic Fatty Liver Disease in Individuals of European Descent. Gastroenterology 2016;150:12191230. doi:10.1053/j.gastro.2016.01.032
26. Stattermayer AF, Ferenci P. Effect of IL28B genotype on hepatitis B and C virus infection. Curr Opin Virol 2015;14:50-55. doi:10.1016/j. coviro.2015.07.011

27. Zheng H, Li M, Chi B, Wu XX, Wang J, Liu DW. IL28B rs12980275 variant as a predictor of sustained virologic response to pegylatedinterferon and ribavirin in chronic hepatitis $\mathrm{C}$ patients: A systematic review and meta-analysis. Clin Res Hepatol Gastroenterol 2015;39:576583. doi:10.1016/j.clinre.2015.01.009

28. Bota S, Sporea I, Sirli R, Neghina AM, Popescu A, Strain M. Role of interleukin-28B polymorphism as a predictor of sustained virological response in patients with chronic hepatitis $\mathrm{C}$ treated with triple therapy: a systematic review and meta-analysis. Clin Drug Investig 2013;33:325-331. doi:10.1007/s40261-013-0074-0

29. Noureddin M, Wright EC, Alter HJ, et al. Association of IL28B genotype with fibrosis progression and clinical outcomes in patients with chronic hepatitis C: a longitudinal analysis. Hepatology 2013;58:1548-1557. doi:10.1002/hep.26506

30. Zhang Y, Zhu SL, Chen J, Li LQ. Meta-analysis of associations of interleukin-28B polymorphisms rs8099917 and rs12979860 with development of hepatitis virus-related hepatocellular carcinoma. Onco Targets Ther 2016;9:3249-3257. doi:10.2147/OTT.S104904

31. Kai AK, Chan LK, Lo RC, et al. Down-regulation of TIMP2 by HIF-1alpha/miR-210/HIF-3alpha regulatory feedback circuit enhances cancer metastasis in hepatocellular carcinoma. Hepatology 2016;64:473-487. doi:10.1002/hep.28577

32. Zhang $\mathrm{X}$, Feng M, Liu $\mathrm{X}$, et al. Persistence of cirrhosis is maintained by intrahepatic regulatory $\mathrm{T}$ cells that inhibit fibrosis resolution by regulating the balance of tissue inhibitors of metalloproteinases and matrix metalloproteinases. Transl Res 2016;169:62-79. doi:10.1016/j. trsi.2015.10.008

33. Luedde T, Schwabe RF. NF- $\kappa B$ in the liver-linking injury, fibrosis and hepatocellular carcinoma. Nat Rev Gastroenterol Hepatol 2011;8:108118. doi:10.1038/nrgastro.2010.213

34. Fakhir FZ, Lkhider M, Badre W, et al. The -94Ins/DelATTG polymorphism in NFkappaB1 promoter modulates chronic hepatitis $\mathrm{C}$ and liver disease progression. Infect Genet Evol 2016;39:141-146. doi:10.1016/j.meegid.2016.01.023

35. Ravaioli F, Montagnani M, Lisotti A, Festi D, Mazzella G, Azzaroli F. Noninvasive Assessment of Portal Hypertension in Advanced Chronic Liver Disease: An Update. Gastroenterol Res Pract 2018;2018:4202091. doi:10.1155/2018/4202091

36. Reig M, Mariño Z, Perelló C, et al. Unexpected high rate of early tumor recurrence in patients with HCV-related HCC undergoing interferonfree therapy. J Hepatol 2016;65:719-726. doi:10.1016/j.jhep.2016.04.008

37. ANRS collaborative study group on hepatocellular carcinoma (ANRS CO22 HEPATHER CC and CC cohorts). Lack of evidence of an effect of direct-acting antivirals on the recurrence of hepatocellular carcinoma: Data from three ANRS cohorts. J Hepatol 2016;65:734-740. doi:10.1016/j.jhep.2016.05.045

38. Ogawa E, Furusyo N, Nomura H, et al. Short-term risk of hepatocellular carcinoma after hepatitis $\mathrm{C}$ virus eradication following direct-acting anti-viral treatment. Aliment Pharmacol Ther 2018;47:104-113. doi:10.1111/apt.14380

39. Li DK, Ren Y, Fierer DS, et al. The short-term incidence of hepatocellular carcinoma is not increased after hepatitis $\mathrm{C}$ treatment with directacting antivirals: An ERCHIVES study. Hepatology 2018;67:2244-2253. doi:10.1002/hep.29707

40. van der Meer AJ, Feld JJ, Hofer H, et al. Risk of cirrhosis-related complications in patients with advanced fibrosis following hepatitis 
C virus eradication. J Hepatol 2017;66:485-493. doi:10.1016/j. jhep.2016.10.017

41. Nahon P, Bourcier V, Layese R, et al. Eradication of Hepatitis C Virus Infection in Patients With Cirrhosis Reduces Risk of Liver and Non-Liver Complications. Gastroenterology 2017;152:142-156. doi:10.1053/j.gastro.2016.09.009

42. Innes H, Barclay ST, Hayes PC, et al. The risk of hepatocellular carcinoma in cirrhotic patients with hepatitis $\mathrm{C}$ and sustained viral response: role of the treatment regimen. J Hepatol 2018;68:646-654. doi:10.1016/j. jhep.2017.10.033

43. Nagata $H$, Nakagawa M, Asahina $Y$, et al. Effect of interferon-based and -free therapy on early occurrence and recurrence of hepatocellular carcinoma in chronic hepatitis C. J Hepatol 2017;67:933-939. doi:10.1016/j.jhep.2017.05.028

44. Petta S, Cabibbo G, Barbara M, et al. Hepatocellular carcinoma recurrence in patients with curative resection or ablation: impact of HCV eradication does not depend on the use of interferon. Aliment Pharmacol Ther 2017;45:160-168. doi:10.1111/apt.13821

45. Criqui MH, Bangdiwala S, Goodman DS, et al. Selenium, retinol, retinolbinding protein, and uric acid. Associations with cancer mortality in a population-based prospective case-control study. Ann Epidemiol 1991;1:385-393. doi:10.1016/1047-2797(91)90008-Z

46. Jiao C, Cui L, Ma A, Li N, Si H. Elevated Serum Levels of RetinolBinding Protein 4 Are Associated with Breast Cancer Risk: A CaseControl Study. PLoS One 2016;11:e0167498. doi:10.1371/journal. pone. 0167498

47. Nash SH, Till C, Song X, et al. Serum Retinol and Carotenoid Concentrations and Prostate Cancer Risk: Results from the Prostate Cancer Prevention Trial. Cancer Epidemiol Biomarkers Prev 2015;24:1507-1515. doi:10.1158/1055-9965.EPI-15-0394

48. Ukleja A, Scolapio JS, McConnell JP, et al. Nutritional assessment of serum and hepatic vitamin A levels in patients with cirrhosis. JPEN J Parenter Enteral Nutr 2002;26:184-188. doi:10.1177/0148607102026003184

49. Hayes CN, Imamura M, Aikata H, Chayama K. Genetics of IL28B and HCV--response to infection and treatment. Nat Rev Gastroenterol Hepatol 2012;9:406-417. doi:10.1038/nrgastro.2012.101

50. Chen Y, Xu HX, Wang LJ, Liu XX, Mahato RI, Zhao YR. Metaanalysis: IL28B polymorphisms predict sustained viral response in HCV patients treated with pegylated interferon-alpha and ribavirin. Aliment Pharmacol Ther 2012;36:91-103. doi:10.1111/j.13652036.2012.05131.x

51. Gutierrez JA, Lawitz EJ, Poordad F. Interferon-free, direct-acting antiviral therapy for chronic hepatitis C. J Viral Hepat 2015;22:861-870. doi:10.1111/jvh.12422

52. Li Q, Kawamura K, Tada Y, Shimada H, Hiroshima K, Tagawa M. Novel type III interferons produce anti-tumor effects through multiple functions. Front Biosci (Landmark Ed) 2013;18:909-918. doi: $10.2741 / 4152$

53. Boisvert M, Shoukry NH. Type III Interferons in Hepatitis C Virus Infection. Front Immunol 2016;7:628. doi:10.3389/fimmu.2016.00628
54. Ank N, West H, Paludan SR. IFN- $\lambda$ : Novel Antiviral Cytokines. J Interferon Cytokine Res 2006;26:373-379. doi:10.1089/jir.2006.26.373

55. Wei X, Jia ZS, Lian JQ, et al. Inhibition of Hepatitis C Virus Infection by Interferon- $\gamma$ Through Downregulating Claudin-1.J Interferon Cytokine Res 2009;29:171-178. doi:10.1089/jir.2008.0040

56. Robek MD, Boyd BS, Chisari FV. Lambda Interferon Inhibits Hepatitis B and C Virus Replication. J Virol 2005;79:3851-3854. doi:10.1128/ JVI.79.6.3851-3854.2005

57. Grünvogel O, Esser-Nobis K, Reustle A, et al. DDX60L Is an InterferonStimulated Gene Product Restricting Hepatitis C Virus Replication in Cell Culture. J Virol 2015;89:10548-10568. doi:10.1128/JVI.01297-15

58. Fabris C, Falleti E, Cussigh A, et al. IL-28B rs12979860 C/T allele distribution in patients with liver cirrhosis: Role in the course of chronic viral hepatitis and the development of HCC. J Hepatol 2011;54:716-722. doi:10.1016/j.jhep.2010.07.019

59. Donnelly RP, Kotenko SV. Interferon-lambda: a new addition to an old family. J Interferon Cytokine Res 2010;30:555-564. doi:10.1089/ jir.2010.0078

60. Laidlaw SM, Dustin LB. Interferon lambda: opportunities, risks, and uncertainties in the fight against HCV. Front Immunol 2014;5:545. doi:10.3389/fimmu.2014.00545

61. Bruno S, Thompson AJ, Critelli R, et al. Interferon lambda-3 is not associated with clinical outcome in patients with HCV-induced compensated cirrhosis: a long-term cohort study. Antivir Res 2015;113:27-32. doi:10.1016/j.antiviral.2014.11.002

62. Chang KC, Tseng PL, Wu YY, et al. A polymorphism in interferon L3 is an independent risk factor for development of hepatocellular carcinoma after treatment of hepatitis C virus infection. Clin Gastroenterol Hepatol 2015;13:1017-1024. doi:10.1016/j.cgh.2014.10.035

63. Matsuura K, Sawai H, Ikeo K, et al. Genome-Wide Association Study Identifies TLL1 Variant Associated With Development of Hepatocellular Carcinoma After Eradication of Hepatitis C Virus Infection. Gastroenterology 2017;152:1383-1394. doi:10.1053/j. gastro.2017.01.041

64. Huang CF, Huang CY, Yeh ML, et al. Genetics Variants and Serum Levels of MHC Class I Chain-related A in Predicting Hepatocellular Carcinoma Development in Chronic Hepatitis C Patients Post Antiviral Treatment. EBioMedicine 2017;15:81-89. doi:10.1016/j. ebiom.2016.11.031

65. Bandiera S, Billie Bian C, Hoshida Y, Baumert TF, Zeisel MB. Chronic hepatitis $\mathrm{C}$ virus infection and pathogenesis of hepatocellular carcinoma. Curr Opin Virol 2016;20:99-105. doi:10.1016/j.coviro.2016.09.010

66. Ravaioli F, Conti F, Brillanti S, et al. Hepatocellular carcinoma risk assessment by the measurement of liver stiffness variations in HCV cirrhotics treated with direct acting antivirals. Dig Liver Dis 2018;50:573-579. doi:10.1016/j.dld.2018.02.010

67. Casadei Gardini A, Foschi FG, Conti F, et al. Immune inflammation indicators and ALBI score to predict liver cancer in HCV-patients treated with direct-acting antivirals. Dig Liver Dis 2019;51:681-688. doi:10.1016/j.dld.2018.09.016 